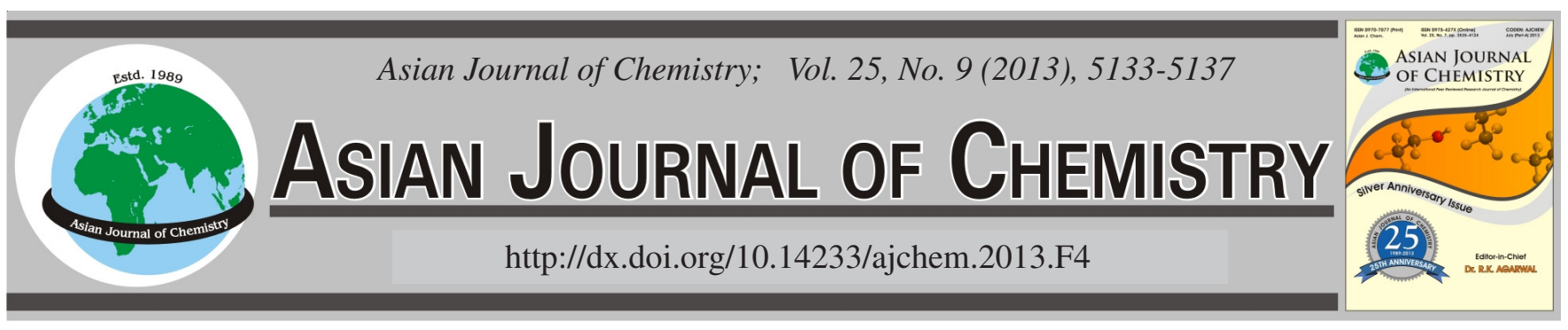

\title{
Reliability Evaluation of Rubber Component $\dagger$
}

\author{
C.S. Woo ${ }^{1, *}$, W.D. KIM ${ }^{1}$, H.S. PARK ${ }^{1}$ and S.B. LEE ${ }^{2}$
}

\begin{abstract}
${ }^{1}$ Department of Nano Mechanics, Korea Institute of Machinery and Materials, Daejeon, Republic of Korea ${ }^{2}$ Department of Mechanical and Automotive Engineering, High Safety Vehicle Core Technology Research Center, Inje University, Gimhae, Republic of Korea
\end{abstract}

*Corresponding author: Fax: +82 42 8687884; Tel: +82 42 8687882; E-mail: cswoo@kimm.re.kr

\begin{abstract}
The rubber material properties and useful lifetime evaluation are very important in design procedures to ensure the safety and reliability of rubber components. This study examined experimentally the characteristics and useful lifetime prediction of rubber components for an elevator cabin. Material tests and accelerated heat-aging tests were conducted. The rubber material coefficient was obtained by curve fitting of uni-axial tension, pure shear and equi-biaxial tension test data. To assess and predict the useful lifetime of natural rubber component, the changes in mechanical properties were determined under accelerated aging conditions. The rubber was aged at temperatures ranging from $70{ }^{\circ} \mathrm{C}$ to $100{ }^{\circ} \mathrm{C}$ for between 1 and 60 days. This paper presents a general approach for correlating the accelerated aging results with aging under service conditions using an Arrhenius methodology. Several useful lifetime prediction equations for the rubber component were proposed using the rubber material and component test. The predicted useful lifetime of the rubber component for an elevator cabin agreed fairly well with the experimentally determined values.
\end{abstract}

Key Words: Rubber component, Reliability, Finite element analysis, Acceleration test.

\section{INTRODUCTION}

Rubber is one of the most versatile materials used widely in numerous applications in daily life, such as simple household, commercial and automotive products to more complex uses in the aviation and space industries.

The interest in the useful lifetime evaluation for the rubber component has increasing according to the extension of the warranty period $^{1,2}$. The design of a rubber component against failure is one of the critical issues for preventing failure during operation. Therefore, a lifetime prediction and evaluation are technological requirements to ensure the safety and reliability of mechanical rubber components ${ }^{3,4}$.

This study examined experimentally the characteristics and useful lifetime prediction of a rubber component for an elevator cabin, as shown in Fig. 1. When rubber is used for long periods, it normally becomes hardened and losses its damping capacity. This aging process results mainly from heat due to hysteric loss and affects not only the material properties but also the useful lifetime of rubber components.

The stress-strain curves were obtained from the material tests to examine the heat-ageing effects on the material properties. In addition, accelerated heat aging tests were carried out to predict the useful lifetime of the rubber component for an elevator cabin. Several useful lifetime prediction equations for the rubber component were proposed using the rubber material and component test.

\section{EXPERIMENTAL}

The materials of the rubber component for the elevator cabin were carbon-filled vulcanized natural rubber, which have a hardness of IRHD 40. The rubber material properties, which are essential in finite element analysis, are expressed as the coefficient of the strain energy function and are determined by fitting the stress-strain data obtained from the material test under various loads to the stress-strain curve induced from the strain energy function. This is also determined to minimize the differences between the test and calculated values. Therefore, the material properties were analyzed and the nonlinear material coefficient, which is essential in finite element analysis, was determined by conducting uni-axial tension, equi-biaxial tension and pure shear tests 5 .

Fig. 2(a) shows the uni-axial tension test using the noncontacting strain measurements (laser extensometer). In the uni-axial compression test, it is very difficult to obtain the pure compressed stress-strain relationship because of friction 

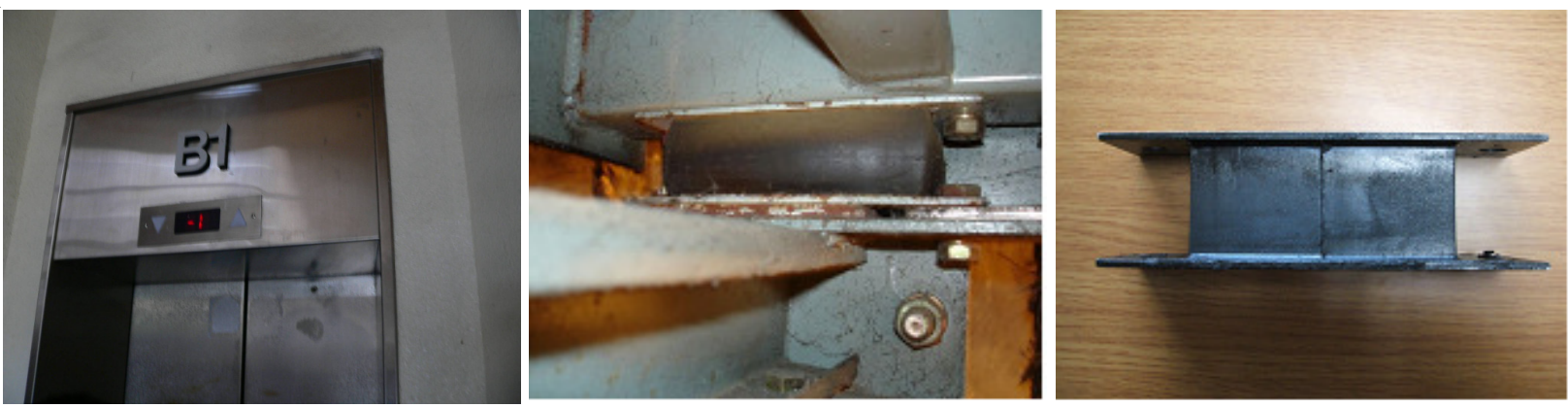

Fig. 1. Rubber component for elevator cabin
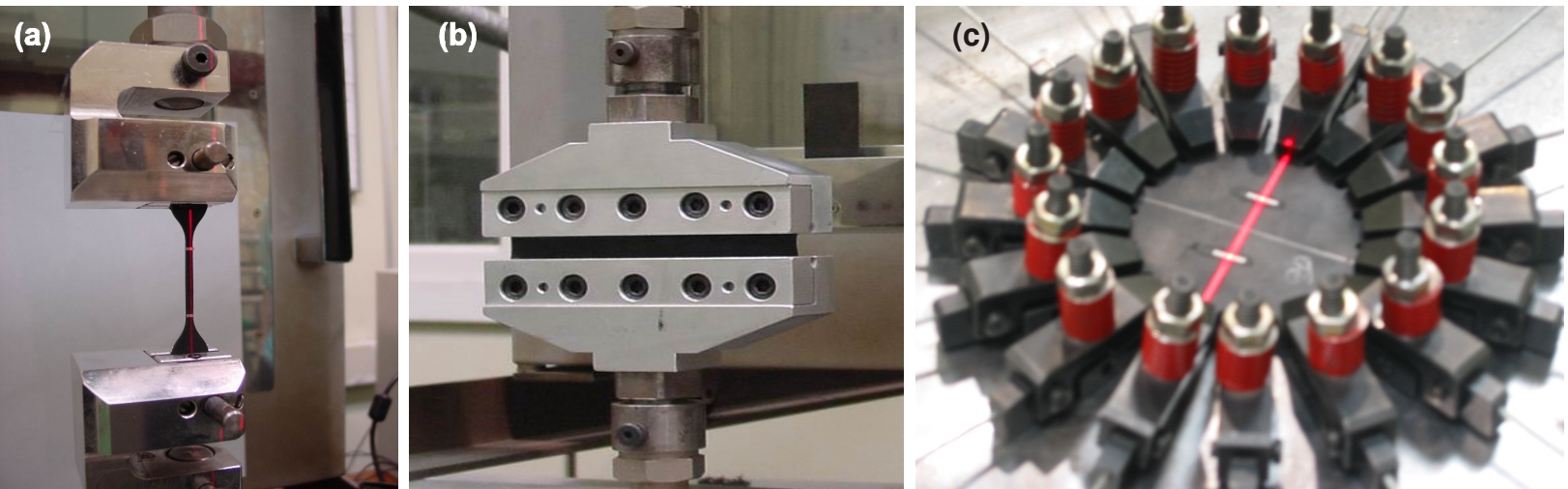

Fig. 2. Physical test of rubber material (a) Uni-axial tension (b) Pure shear (c) Equi-biaxial tension
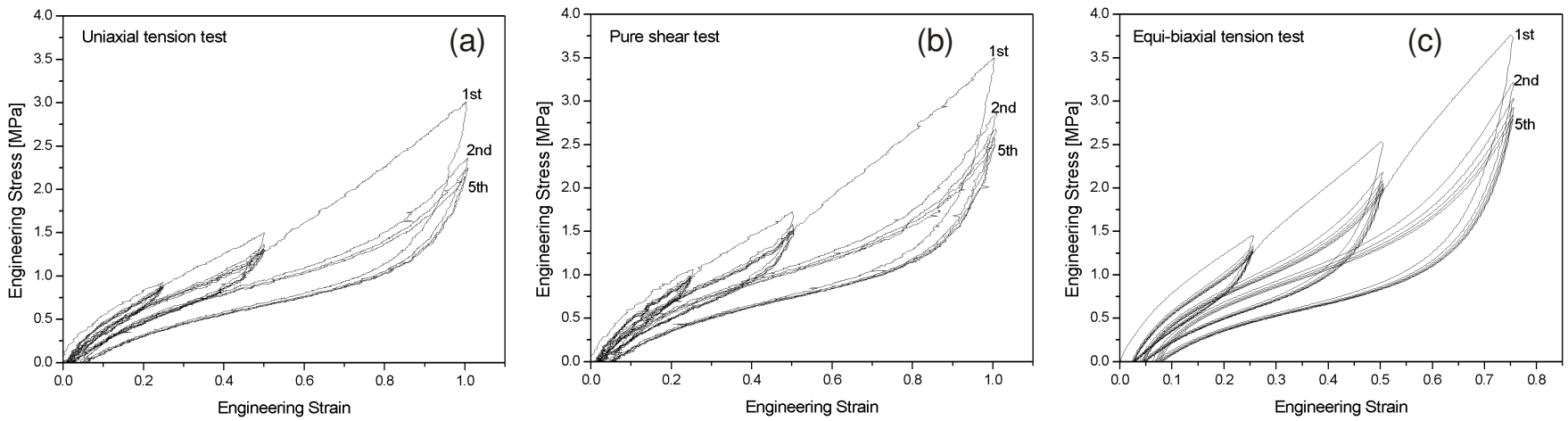

Fig. 3. Stress-strain curve at various strain range; (a) Uni-axial tension (b) Pure shear (c) Equi-biaxial tension

on the grip and the contact plane of the rubber test specimen. In addition, there is some bubbling phenomenon in the middle part of the test sample due to this friction. Therefore, it is difficult to say that the properties of the materials obtained from the uni-axial compression test are accurate. Therefore, Kim et al. ${ }^{8}$ suggested that equi-biaxial tension tests, in which the pure strain values can be obtained, are more preferred for resolving such issues in the uniaxial compression test. The pure shear test imposes plane strain conditions on the test specimen by preventing the edges of the specimen from contracting. This was achieved using test specimens with high aspect ratios. In the current study, a $100 \mathrm{~mm}$ wide specimen was clamped with a grip separation of $10 \mathrm{~mm}$ using the wide grips shown in Fig. 2(b). Round shaped test specimens were prepared for the equi-biaxial tension tests, as shown in Fig. 2(c).

Fig. 3 shows the stress-strain curves obtained from the physical test with 25,50 and $100 \%$ of the strain range for natural rubber.
To define the hyper-elastic material behaviour, physical test data is required for an accurate calculation of the material parameters in the strain energy potential. The material parameters in the Ogden strain energy potential of the order $\mathrm{N}=3$ represented in eqn. (1) can be determined from the experimental stress-strain data ${ }^{6}$.

$$
\mathrm{W}=\sum_{\mathrm{n}=1}^{\mathrm{N}} \frac{\mu_{\mathrm{n}}}{\alpha_{\mathrm{n}}}\left(\lambda_{1}^{\alpha_{\mathrm{n}}}+\lambda_{2}^{\alpha_{\mathrm{n}}}+\lambda_{3}^{\alpha_{\mathrm{n}}}-3\right)
$$

where $\mu_{\mathrm{i}}$ and $\alpha_{\mathrm{i}}$ are the material parameters and $\lambda_{\mathrm{i}}$ is the principal stretch ratio. The stretch ratio was defined as the ratio of the extended length of a specimen, L, to the un-extended length, $\mathrm{L}_{\mathrm{o}}$. In this study, the material coefficient was obtained by curve fitting of the uni-axial tension, equi-biaxial tension and pure shear test data. Curve fitting with the physical test data was also performed. The Ogden 3-term fits uses progressively more information as the basis for curve fitting. Table-1 lists the rubber material coefficients calculated in each case. 


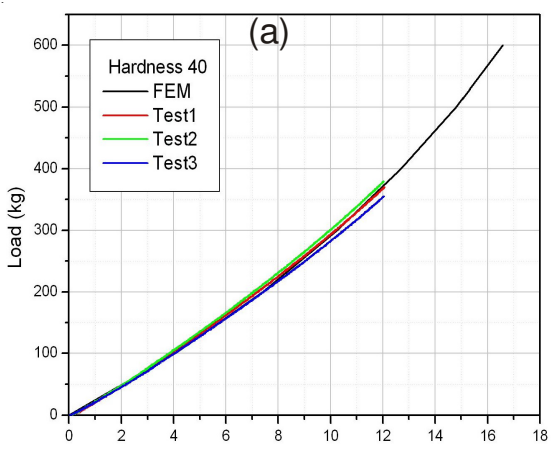

(b)
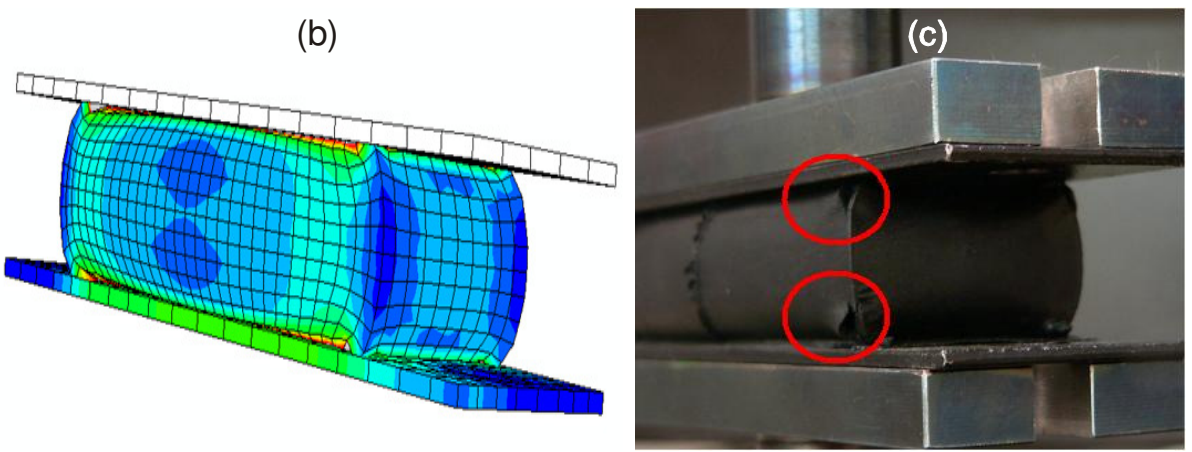

Fig. 4. Finite element analysis of rubber component; (a) Load-displacement (b) Stress distribution (c) Fatigue cracking
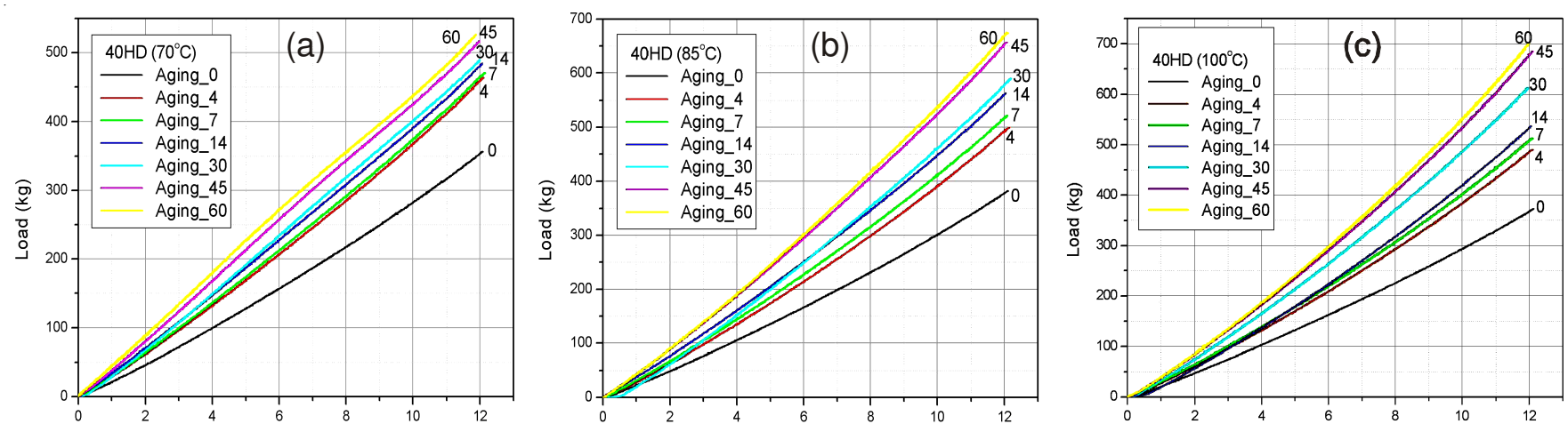

Fig. 5. Load-displacement of rubber component; (a) $70{ }^{\circ} \mathrm{C}$ (b) $85^{\circ} \mathrm{C}$ (c) $100{ }^{\circ} \mathrm{C}$

\begin{tabular}{cccccccc}
\multicolumn{7}{c}{ TABLE-1 } \\
\multicolumn{7}{c}{ OUBBER MATERIAL COEFFICIENT } \\
\hline Strain & \multicolumn{7}{c}{ Og-terms } \\
\cline { 2 - 8 }$(\%)$ & $\mu_{1}$ & $\alpha_{1}$ & $\mu_{2}$ & $\alpha_{2}$ & $\mu_{3}$ & $\alpha_{3}$ & G \\
\hline 25 & $2.3 \mathrm{e}-5$ & 1.613 & 0.394 & 2.883 & $1.5 \mathrm{e}-4$ & 0.557 & 0.568 \\
50 & 2.067 & $3.1 \mathrm{e}-6$ & $1.0 \mathrm{e}-5$ & 0.072 & 0.587 & 1.814 & 0.532 \\
100 & 3.504 & 0.066 & 1.303 & 0.008 & 0.364 & 2.118 & 0.507 \\
\hline
\end{tabular}

Finite element analysis was performed to examine the deformation and strain distribution behaviour of the rubber component using a rubber material coefficient. Fig. 4(a) shows the load-displacement curve comparison between the simulations using the hyper-elastic models and static test data. The results of finite element analysis were in good agreement with the experimental test.

Fig. 4(b) shows the stress distributions of the rubber component under a compression load of $6 \mathrm{kN}$. The maximum stress was noted at the edge. Fatigue failure initiated at the critical location was observed during the fatigue test of the rubber component, which was the same result predicted by finite element analysis.

To predict the useful lifetime of the rubber component, the accelerated heat aging test were carried out in an oven at temperatures ranging from $70^{\circ} \mathrm{C}$ to $100{ }^{\circ} \mathrm{C}$ during a period 60 days ${ }^{7}$. Oven aging was carried out in air-circulating ovens (stable and accurate to $c a . \pm 1^{\circ} \mathrm{C}$ ) equipped with thermocouples connected to continuous strip chart recorders. Hardness measurements were performed on heat aging samples using a micro hardness meter. Fig. 5 shows a graphic representation of the load-displacement after heat aging results. The stiffness increased with increasing heat aging temperature and time. Fig. 6 shows the change in properties (hardness, spring constant relationship) with time at different temperatures.

\section{RESULTS AND DISCUSSION}

Predicting the useful lifetimes has been a major challenge for the polymer industry. The Arrhenius methodology is commonly used to predict the material lifetimes by extrapolating the results at higher temperatures.

This approach models the physical degradation of interest as a result of an activated chemical process, such that the rate is proportional to $\exp (-\mathrm{E} / \mathrm{RT})$, where $\mathrm{E}$ is the Arrhenius activation energy, $\mathrm{R}$ is the gas constant and $\mathrm{T}$ is the absolute temperature. Where appropriate, this method predicts a linear relationship between the logarithm of time to a specified material property change and the reciprocal of the absolute temperature. The reaction rate at any temperature was obtained from the change in the selected properties with the exposure time at that temperature. Using the accelerated aging test and Arrhenius methodology, the useful lifetime to the threshold value $(15,20,50$ and $100 \%)$ was plotted as a function of the reciprocal absolute temperature, as shown in Fig. 7. Using the Arrhenius plot, several useful lifetime prediction equations for the rubber component were proposed, as listed in Table-2. The useful lifetime of the rubber component for the elevator cabin was predicted to be approximately 5.9 years with a $15 \%$ decrease in hardness and 6.0 years with a $100 \%$ decrease in spring constant.

The characteristic test for actual used-rubber components was carried out to evaluate the useful lifetime for rubber component. From the results of the experimental test, a $15 \%$ and $100 \%$ change in hardness and spring constant, respectively, occurred at approximately 6 years (Fig. 8). The predicted lives were in a good agreement with the experimental lives. 

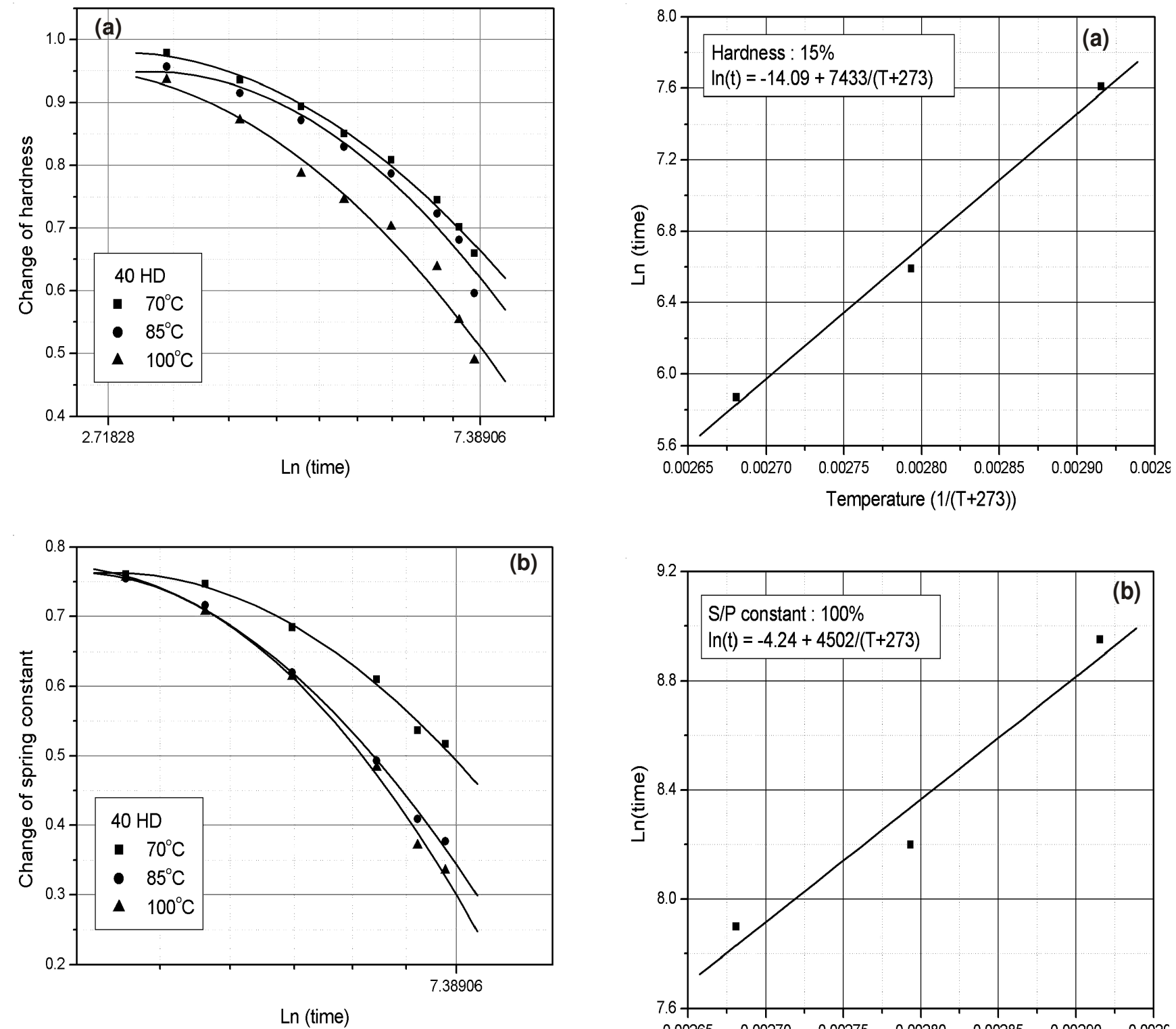

Fig. 6. Chang of properties according to the time; (a) Hardness (b) Spring constant
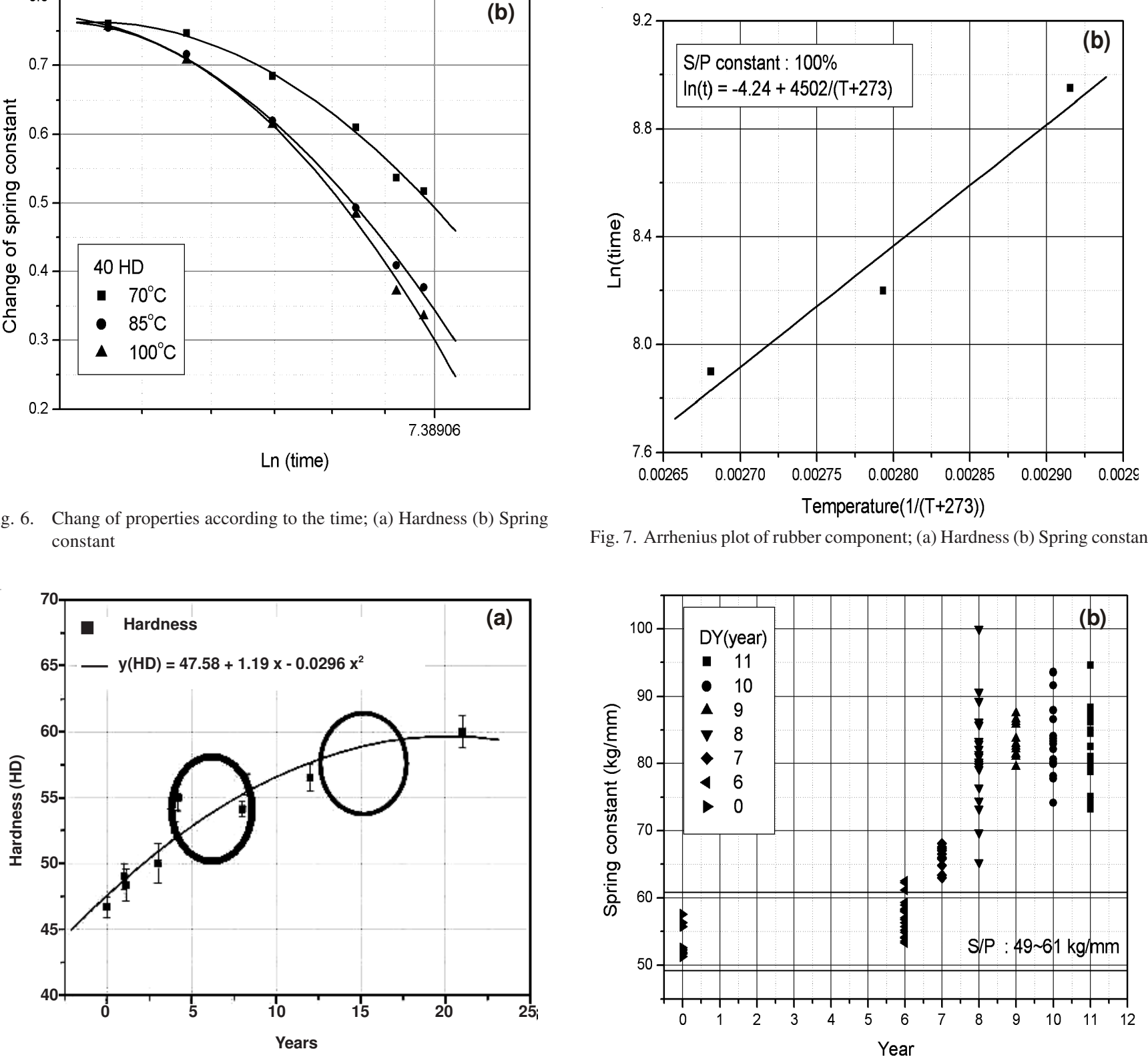

Fig. 8 Characteristic of used-rubber component; (a) Hardness (b) Spring constant 
TABLE-2

USEFUL LIFETIME PREDICTION OF THE RUBBER COMPONENT

\begin{tabular}{cccc}
\hline Property & $\begin{array}{c}\text { Change } \\
(\%)\end{array}$ & Life prediction equation & $\begin{array}{c}\text { Lifetime } \\
(\text { year })\end{array}$ \\
\hline Hardness & 15 & $\operatorname{In}(\mathrm{t})=-14.1+7433 /(\mathrm{T}+273)$ & 5.9 \\
& 20 & $\operatorname{In}(\mathrm{t})=-15.4+8099 /(\mathrm{T}+273)$ & 14.7 \\
\hline Spring & 50 & $\operatorname{In}(\mathrm{t})=-4.03+3961 /(\mathrm{T}+273)$ & 1.2 \\
constant & 100 & $\operatorname{In}(\mathrm{t})=-4.24+4502 /(\mathrm{T}+273)$ & 6.0 \\
\hline
\end{tabular}

\section{Conclusion}

A useful lifetime prediction and evaluation are the key technologies for ensuring the safety and reliability of rubber components. In this paper, predictions of the characteristics and useful lifetime of the rubber component for an elevator cabin were examined experimentally. The rubber material coefficient was obtained by curve fitting the results of the uniaxial tension, equi-biaxial tension and pure shear tests. The relationships between the applied load and displacement were obtained from finite element analysis. The results the finite element analysis are a good agreement with the experimental data. Several useful lifetime prediction equations for the rubber component were proposed using the accelerated heat-aging test. The useful lifetime of the rubber component was predicted to be approximately 6 years for a $15 \%$ decrease in hardness and a $100 \%$ decrease in spring constant. The predicted lives were in a good agreement with the experimental lives.

\section{ACKNOWLEDGEMENTS}

This study was supported by Ministry of Knowledge Economy.

\section{REFERENCES}

1. R.E. Frederick, Rubber Div. Am. Chem. Soc., 62 (1982).

2. G.J. Lake, Rubber Chem. Technol., 68, 435 (1997).

3. K. Takeuchi and M. Nagakawa, Int. Polym. Sci., 20, 64 (1993).

4. R.P. Brown, Rapra Review Reports, Vol. 13, No. 3, Report 147 (2002).

5. R.P. Brown, Physical Testing of Rubber, Rapra Technology Ltd., Shewbury (1996).

6. A.K. Mal and S.J. Singh, Deformation of Elastic Solids, Prentice Fall PTR (1990).

7. R.P. Brown and T. Butler, Natural Ageing of Rubber-Changes in Physical Properties over 40 Year's, Rapra Technology Ltd., Shewbury (2001).

8. W.D. Kim, D.J. Kim, W.S. Kim and Y.S. Lee, J. Korean Soc. Automotive Eng., 11, 95 (2003) 